therapists working in this country trained there. It also runs a unique course in psychosocial nursing.

Plans to shut the Cassel announced at the start of 1990 were widely criticised. At the health authority's meeting in February, district manager Mr Knowles while proposing closure, at the same time suggested a scheme for fund raising and preparing a business plan that would ensure the Cassel's safety until April 1991, when it would be able to test itself out in the new conditions of the NHS 'open market'. A three month consultation period began. The hospital received the services of a financial manager to help in preparing a package to raise $£ 300,000$ within the year and draw up a business plan for use in the internal market from next April.

During the consultation period the hospital was widely supported by former patients, the media, poli- ticians, the general public and other colleagues. As a result, the district health authority withdrew their closure proposals in June, although the need to raise $£ 300,000$, the hospital's share of cuts applied across Riverside remains. Any shortfall in fund raising by April 1991 will become a charge on the hospital's operating costs, and may eventually lead to equivalent cuts in the service as originally put forward in February. Fund-raising measures are likely to include soliciting donations and perhaps a public appeal, properly costed training and consultations and a small number of private patients, up to $10 \%$ of in and out-patients. The Cassel must change but its survival has once more been guaranteed.

See Correspondence, p. 40.

\title{
Non attenders at a marital and sexual difficulties clinic
}

\author{
R. Huws, Senior Registrar in Psychiatry, Marital and Sexual Difficulties Clinic, \\ Whitely Wood Clinic, Woofinden Road, Sheffield S10 3TL
}

The Marital and Sexual Difficulties Clinic at Sheffield offers out-patient treatment that is usually based on a modified Masters \& Johnson method. This consists of behavioural techniques, notably sensate focus, used within a psychoanalytic background.

A study of 339 clients referred to a sexual dysfunction clinic (Forday-Settlage, 1975), found a $41 \%$ nonattendance rate for the first appointment. Bancroft \& Coles (1976) looked at 275 referrals to the sexual problem clinic at Oxford in the three years up to 1975 . Of these, $75(27 \%)$ did not attend the first appointment. Neither study compared the characteristics of attenders with non-attenders.

Hillis \& Alexander (1990) compared 129 nonattenders to a psychiatric clinic with 100 attenders. Sociodemographic factors did not play a significant part in non-attendance. Patients were more likely to attend if they received a letter rather than a standard appointment card $(P<0.05)$, if they had a previous psychiatric history $(P<0.05)$ or if the appointment was at a mental health centre rather than at a psychiatric hospital $(P<0.02)$. Other studies suggest that absences are due to an interaction of demographic variables, presenting problem and treatment variables. Swenson \& Pekarik (1988) aimed to reduce non-attendance at an initial interview at a community mental health centre by the use of letter prompts. They found that intervention by letter was a successful and practical way to decrease nonattendance. For the health centre, the intervention was cost effective, but as Swenson \& Pekarik point out, for a service with a lower rate of non-attendance this would not necessarily be the case. It might therefore be more useful to target intervention towards certain groups.

The present study examines the demographic characteristics of attenders and non attenders at the Marital and Sexual Difficulties Clinic with the aim of determining if it is possible to target key groups for intervention.

\section{Findings}

The referrals for one year were examined. Out of 269 referrals, 145 attended (54\%). Often the referral letters did not give a clear picture of the problem. In $81 \%$ of the male referrals the problem stated was impotence and in $83 \%$ of the female referrals the problem was lack of interest in sex. There was no difference between attenders and non attenders in 
this respect. Of referrals, $71 \%$ were from general practitioners, $16 \%$ from other medical disciplines, mainly from the urology and the diabetic clinics, and $13 \%$ from mental health workers. Of clients referred by mental health workers, $64 \%$ attended, compared with $55 \%$ of referrals from medical disciplines and $52 \%$ of GP referrals. There was therefore a nonsignificant trend for mental health worker referrals to attend. Of the referrals, $40 \%$ were from outside Sheffield, including some from up to 70 miles away; however there was no difference in the attendance rate. The age range of attenders ranged from 16 to 85 with a mean of 40 , and for non-attenders a mean age of 41 with a range of 19 to 67 years. In $40 \%$ of the referrals a man was identified as the client, a couple in $40 \%$ and a woman in $20 \%$ of cases. If a couple was referred they were more likely to attend and if a woman was the index patient then she was less likely to attend $\left(\chi^{2}=7.54, P<0.05\right)$.

\section{Comment}

The number of non-attenders, at $54 \%$, was high when compared to the two previous reports of attendance at sexual difficulties clinics. Many people find discussing sexual problems with a professional embarrassing and the fact that the clinic is situated in a psychiatric unit may add to this feeling. In other cases the problem might have been resolved, as the mere fact of being referred confirms the existence of a problem, and acknowledging this may be enough for some couples to resolve the problem themselves.

As in previous studies of non-attendance, sociodemographic details did not discriminate between the two groups. There was a non significant trend towards attendance for secondary referrals from mental health workers. This may reflect a greater commitment on the part of that client group rather than an ability on behalf of those workers to pick out likely attenders. The only significant difference was that if a couple was referred, then they were more likely to attend. A woman referred as the index patient was less likely to attend. The clinic is geared towards treating marital and sexual problems as a problem for the couple and the standard appointment letter asks that clients bring their partners with them. It may be that individuals outside a relationship would be dissuaded from attending following receiving such a letter. However, it is more likely that if the referring agent or the couple already see the problem in terms of their relationship, then their commitment to attend is likely to be higher.

This would also explain the lower attendance when a woman is the identified client. Loss of interest in sex is a common presenting problem for women and it is a generally held view that this is primarily the woman's problem rather than being indicative of problems in the relationship. The referrer may well collude with this. The high degree of non-attendance may reflect misgivings on behalf of the woman that the problem is being viewed in this light, or a reluctance on behalf of the male partner to attend if he himself feels that he has no problem. Individually referred men were more likely to attend than women. Of these referrals, 19 were from the urology clinic, where they had been referred for the treatment of impotence and of these $63 \%$ attended. While the numbers are too small for statistical analysis, the percentage attending is similar to those from mental health workers and may represent a more motivated client group.

Due to greater contact, mental health workers and the urology clinic have a greater understanding of what the clinic has to offer, and although there was a trend towards higher attendance from these sources this was not statistically significant.

These results, together with previous work on the subject, would suggest that it may not be possible to target key groups for intervention.

\section{References}

BANCROFT, J. \& COLES, L. (1976) Three years' experience in a sexual problem clinic. British Medical Journal, 1, 1575-1577.

FORDAY-SETTLAGE, D. S. (1975) Heterosexual dysfunction: evaluation of treatment procedures. Archives of Sexual Behaviour, 4, 367-387.

Hillis, G. \& AleXander, D. A. (1990) Rejection of psychiatric treatment. Psychiatric Bulletin, 14, 149-150.

Swenson, T. R. \& Pekarik, G. (1988) Interventions for reducing missed initial appointments at a Community Mental Health Center. Community Mental Health Journal, 24, 205-218. 